Check for updates

Cite this: RSC Adv., 2019, 9, 6568

Received 19th December 2018 Accepted 10th February 2019

DOI: $10.1039 / c 8 r a 10397 f$

rsc.li/rsc-advances

\section{Ultradispersed titanium dioxide nanoparticles embedded in a three-dimensional graphene aerogel for high performance sulfur cathodes $\uparrow$}

\author{
Mengmeng Liu, ${ }^{a}$ Xiaohang Zhu, ${ }^{a}$ Tianye $\mathrm{Ma},{ }^{a}$ Congcong Zhang, (D) ${ }^{a}$ Xiang Chen, ${ }^{a}$ \\ Xiuhui Zhang, ${ }^{b}$ Tao Huang, ${ }^{a}$ Wei Li (D)*b and Aishui Yu (D)*ab
}

\begin{abstract}
Lithium-sulfur (Li-S) batteries are regarded as one of the most promising energy storage technologies, however, their practical application is greatly limited by a series of sulfur cathode challenges such as the notorious "shuttle effect", low conductivity and large volume change. Here, we develop a facile hydrothermal method for the large scale synthesis of sulfur hosts consisting of three-dimensional graphene aerogel with tiny $\mathrm{TiO}_{2}$ nanoparticles $(5-10 \mathrm{~nm})$ uniformly dispersed on the graphene sheet $\left(\mathrm{GA}-\mathrm{TiO}_{2}\right)$. The obtained $\mathrm{GA}-\mathrm{TiO}_{2}$ composites have a high surface area of $\sim 360 \mathrm{~m}^{2} \mathrm{~g}^{-1}$ and a hierarchical porous structure, which facilitates the encapsulation of sulfur in the carbon matrix. The resultant $\mathrm{GA}-\mathrm{TiO}_{2} / \mathrm{S}$ composites exhibit a high initial discharge capacity of $810 \mathrm{~mA} \mathrm{~h} \mathrm{~g} \mathrm{~g}^{-1}$ with an ultralow capacity fading of $0.054 \%$ per cycle over 700 cycles at $2 \mathrm{C}$, and a high rate $(5 \mathrm{C}$ ) performance (396 mA h g${ }^{-1}$ ). Such architecture design paves a new way to synthesize well-defined sulfur hosts to tackle the challenges for high performance Li-S batteries.
\end{abstract}

\section{Introduction}

Lithium-sulfur (Li-S) batteries have been gaining global attention because of their high theoretical specific capacity (1675 $\mathrm{mA} \mathrm{h} \mathrm{g}^{-1}$ ), low cost and environmentally friendly nature. Nevertheless, Li-S batteries suffer from some inherent limitations such as poor conductivity of pristine $\mathrm{S}$ and discharge products $\left(\mathrm{Li}_{2} \mathrm{~S}_{2}\right.$ and $\left.\mathrm{Li}_{2} \mathrm{~S}\right)$, large volumetric change, and high solubility of the intermediate lithium polysulfides (LiPSs). ${ }^{1-5}$ These disadvantages usually lead to low $\mathrm{S}$ utilization and poor cycling stability.

To tackle these challenges, tremendous efforts have been devoted to synthesizing various carbon materials as sulfur hosts due to their high electrical conductivity and good interfacial compatibility with S. ${ }^{6-8}$ Among them, graphene has been considered as a promising candidate because of its excellent mechanical properties and large surface areas. ${ }^{9}$ However, the graphene with a lamellar structure is easy to stack so that it is inconducive to the infusion and encapsulation of sulfur. Compared with traditional graphene, three-dimensional (3D)

${ }^{a}$ Laboratory of Advanced Materials, Fudan University, Shanghai 200438, China. E-mail: asyu@fudan.edu.cn; Tel: +86-21-31249125

${ }^{b}$ Department of Chemistry, Shanghai Key Laboratory of Molecular Catalysis and Innovative Materials, Collaborative Innovation Center of Chemistry for Energy Materials, Fudan University, Shanghai 200438, China. E-mail: weilichem@fudan. edu.cn; Tel: +86-21-51630324

$\dagger$ Electronic supplementary information (ESI) available. See DOI: $10.1039 / \mathrm{c} 8 \mathrm{ra} 10397 \mathrm{f}$ graphene aerogel (GA) with abundant interlaced channels can not only facilitate the infusion of sulfur, but also provide effective pathways for ion transport and accommodate the volume change during redox progresses. However, the nonpolarity nature of carbon materials cannot effectively confine the polar LiPSs, which would dissolve in electrolyte and then migrate between the cathode and anode causing the notorious "shuttle effect". To mitigate the dissolution of polysulfides, various polar materials, including $\mathrm{V}_{2} \mathrm{O}_{5},{ }^{10} \mathrm{MnO}_{2},{ }^{11} \mathrm{TiO}_{2},{ }^{12,13}$ $\mathrm{Nb}_{2} \mathrm{O}_{5},{ }^{14} \mathrm{ZnO},{ }^{15} \mathrm{TiS}_{2},{ }^{16} \mathrm{TiN}^{17}$ and metal-organic frameworks ${ }^{18,19}$ have been intensively studied because the chemical bonds between these polar materials and active S/LiPSs can prevent $S$ species from escaping out of the host and increase their utilization. ${ }^{20,21}$ Among them, $\mathrm{TiO}_{2}$ is regarded as one of the most promising host to contain $\mathrm{S}$ for its good absorption ability, low cost, high stability and low toxicity. ${ }^{22-24}$ Nevertheless, the low conductivity and poor porosity of $\mathrm{TiO}_{2}$ materials limit their applications..$^{25}$

Herein, we designed and prepared a sulfur host consisting of three-dimensional graphene aerogel with $\mathrm{TiO}_{2}$ nanoparticles (5$10 \mathrm{~nm}$ ) uniformly attached on the graphene sheets (denoted as $\mathrm{GA}^{-\mathrm{TiO}_{2}}$ ) by a facile hydrothermal method and subsequent hightemperature calcination. The resultant $\mathrm{GA}_{-}-\mathrm{TiO}_{2}$ composites possess an interconnected porous structure stacked by the graphene sheets, where the tiny $\mathrm{TiO}_{2}$ nanoparticles disperses uniformly. Its specific surface area is calculated to be $\sim 360 \mathrm{~m}^{2} \mathrm{~g}^{-1}$. As a result, the $\mathrm{GA}-\mathrm{TiO}_{2}$ composites exhibit an excellent electrochemical performance as a cathode material of $\mathrm{Li}-\mathrm{S}$ batteries. A high initial specific capability of $1555 \mathrm{~mA} \mathrm{~h} \mathrm{~g}^{-1}$ and $810 \mathrm{~mA} \mathrm{~h} \mathrm{~g}^{-1}$ 
at $0.2 \mathrm{C}$ and $2 \mathrm{C}$, a good cycling stability with a low capacity fading rate of $0.080 \%$ and $0.054 \%$ per cycle over 500 and 700 cycles, an approaching $100 \%$ coulombic efficiency and an outstanding rate capability are achieved, which are superior to those of the GA cathode.

\section{Experimental section}

\subsection{Preparation of $3 \mathrm{D}$ graphene aerogel-TiO $2\left(\mathrm{GA}^{-\mathrm{TiO}_{2}}\right)$ composites}

The 3D GA- $\mathrm{TiO}_{2}$ composites were prepared by a facile hydrothermal method, combined with a high-temperature treatment. First, graphene oxide (GO) was synthesized from natural graphite powder using a modified Hummers method. ${ }^{30}$ Then, $85.3 \mathrm{mg} \mathrm{Ti}\left(\mathrm{SO}_{4}\right)_{2}$ and $2.4 \mathrm{mg}$ glucose was dissolved in $50 \mathrm{~mL} \mathrm{GO}$ aqueous solution $\left(1.6 \mathrm{~g} \mathrm{~L}^{-1}\right)$ under the magnetic stirring. Next, the mixture solution was transferred into a $100 \mathrm{~mL}$ Teflonsealed autoclave and heated at $180{ }^{\circ} \mathrm{C}$ for $12 \mathrm{~h}$. The asprepared sample was washed with deionized water and ethanol several times, then freeze-dried for $24 \mathrm{~h}$. Finally, the $\mathrm{GA}-\mathrm{TiO}_{2}$ composites were obtained after annealing at $800{ }^{\circ} \mathrm{C}$ for $2 \mathrm{~h}$ in Ar. A series of $\mathrm{GA}-\mathrm{TiO}_{2}$ with different $\mathrm{TiO}_{2}$ loading are denoted as $\mathrm{GA}^{-}-\mathrm{TiO}_{2}-x$ where $x$ wt $\%$ represents the content of the $\mathrm{TiO}_{2}$ and summarized in Table S1. $\dagger$ As a control, GA was synthesized without $\mathrm{Ti}\left(\mathrm{SO}_{4}\right)_{2}$ and glucose under the same conditions.

\subsection{Loading sulfur in $\mathrm{GA}-\mathrm{TiO}_{2}$ composites}

Loading sulfur in $\mathrm{GA}-\mathrm{TiO}_{2}$ composites was conducted by the conventional melt-diffusion method. Briefly, sublimed sulfur powders and $\mathrm{GA}-\mathrm{TiO}_{2}$ composites were homogeneously mixed with a mass ratio of $7: 3$ by milling for $1 \mathrm{~h}$. Then the mixture was heated at $155^{\circ} \mathrm{C}$ with the protection of Ar for $12 \mathrm{~h}$, leading to the formation of $\mathrm{GA}-\mathrm{TiO}_{2} / \mathrm{S}$ composites.

\subsection{Characterizations}

Nitrogen sorption isotherms were measured at $77 \mathrm{~K}$ with a Micromeritics Tristar 2420 analyzer. Samples for nitrogen adsorption/desorption measurements were obtained from the scrapings of multiple samples. All of the samples were degassed under vacuum at $180{ }^{\circ} \mathrm{C}$ for at least $6 \mathrm{~h}$ prior to measurements. The Brunauer-Emmett-Teller (BET) method was utilized to calculate the specific surface areas using adsorption data in a relative pressure range from 0.05 to 0.25 with $R>0.995$. Using the Barrett-Joyner-Halenda (BJH) model, the pore size distributions were derived from the adsorption branches of isotherms, and the total pore volumes $\left(V_{\mathrm{t}}\right)$ were estimated from the adsorbed amount at a relative pressure $P / P_{0}$ of 0.995 . Transmission electron microscopy (TEM) experiments were conducted on a JEOL JEM-2100 F microscope (Japan) operated at $200 \mathrm{kV}$. The samples for the TEM measurements were suspended in ethanol and supported onto a holey carbon membrane on a $\mathrm{Cu}$ grid. Field-emission scanning electron microscopy (FESEM) images were taken on a Hitachi S-4800 microscope. X-ray photoelectron spectroscopy (XPS) was recorded on an AXISULTRA DLD XPS System with MONO Al source.
Photoelectron spectra were recorded by using monochromatic $\mathrm{Al} \mathrm{KR}$ radiation under vacuum at $5 \times 10^{-9} \mathrm{~Pa}$. X-ray diffraction (XRD) patterns were collected by a Bruker D8 powder X-ray diffractometer (Germany) with $\mathrm{Cu} \mathrm{K} \alpha$ radiation $(40 \mathrm{kV}, 40$ $\mathrm{mA}$ ). Thermogravimetric analysis (TG) was conducted in $\mathrm{NETZSCH}, 209 \mathrm{~F} 1$ at a heating rate of $10{ }^{\circ} \mathrm{C} \mathrm{min}^{-1}$ from $35^{\circ} \mathrm{C}$ to $900{ }^{\circ} \mathrm{C}$.

\subsection{Electrochemical measurements}

The electrochemical properties were examined using the CR2016 type coin cells which were assembled inside an Ar-filled glove box. Working electrodes with $\mathrm{S}$ loading $\left(1.8-2 \mathrm{mg} \mathrm{cm}^{-2}\right)$ were prepared by mixing $80 \mathrm{wt} \%$ of active materials, $10 \mathrm{wt} \%$ of Ketjen Black and $10 \mathrm{wt} \%$ of PVDF dissolved in $\mathrm{N}$-methyl-2pyrrolidinone. The well homogeneous slurry was smeared onto an $\mathrm{Al}$ foil coated with carbon current collector (diameter of $12 \mathrm{~mm}$ ). The prepared pole pieces were dried at $60{ }^{\circ} \mathrm{C}$ for $12 \mathrm{~h}$ under vacuum. Lithium bis(trifluoromethylsulfonyl)imide (1 M) dissolved in a mixture of 1,3-dioxolane and 1,2-dimethoxyethane ( $1: 1$ by volume) with $\mathrm{LiNO}_{3}(2 \mathrm{wt} \%)$ as an additive was used as the electrolyte. Celgard 2320 was used as the separator. The ratio of electrolyte to sulfur is $25 \mu \mathrm{L} \mathrm{g}^{-1}$ in the final pole piece. The galvanostatic discharge/charge performance was measured on a Land CT2001A battery test system with the potential ranging from 1.7 to $2.8 \mathrm{~V}$ versus $\mathrm{Li} / \mathrm{Li}^{+}$at room temperature. The current rate values were based on the theoretical capacity of sulfur (1C equals to $1675 \mathrm{~mA} \mathrm{~g}^{-1}$ ). The specific capacity values were calculated based on the mass of sulfur in the final samples. The specific capacity value was calculated based on the mass of sulfur in the final pole piece. Electrochemical impedance spectroscopy (EIS) measurements were carried out on an IM6e electrochemical workstation (ZAHNER-elektrik GmbH \& CoKG, Germany) in a frequency range of $0.1-1 \times 10^{5} \mathrm{~Hz}$ with an amplitude of $5 \mathrm{mV}$. Cycling voltammetry (CV) measurements were performed on a $\mathrm{CHI}$ 660C electrochemical workstation ( $\mathrm{CH}$ Instruments, Inc., USA) at a scanning rate of $0.1 \mathrm{mV} \mathrm{s}^{-1}$ within a potential window of $1.7-2.8 \mathrm{~V}$.

\section{Results and discussion}

The synthesis of $\mathrm{GA}-\mathrm{TiO}_{2} / \mathrm{S}$ composites is illustrated in Fig. 1. Firstly, the $\mathrm{GA}-\mathrm{TiO}_{2}$ composites were prepared via a facile hydrothermal method using $\mathrm{Ti}\left(\mathrm{SO}_{4}\right)_{2}$ as the $\mathrm{Ti}$ precursor and subsequent pyrolysis under Ar. Glucose hinders aggregation of

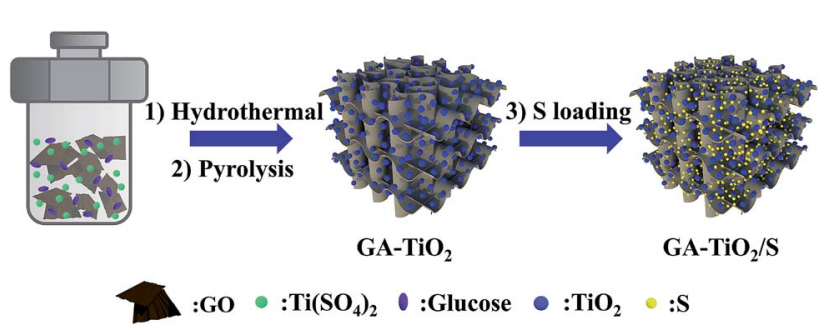

Fig. 1 Schematic illustration of the fabrication process of $\mathrm{GA}-\mathrm{TiO}_{2} / \mathrm{S}$. 
$\mathrm{TiO}_{2}$ nanoparticles and is used as the linker to fix the seeds on the surfaces of GA nanosheets. ${ }^{26}$ Therefore, ultradispersed and small $\mathrm{TiO}_{2}$ nanoparticles were in situ synthesized successfully tightly attached to the GA nanosheets. Then, sulfur was infiltrated into the inner pores of the $\mathrm{GA}^{-\mathrm{TiO}_{2}}$ composites via the conventional melting-diffusion method, leading to the formation of the $\mathrm{GA}-\mathrm{TiO}_{2} / \mathrm{S}$ composites.

The optical image shows that the macroscopic morphology of the $\mathrm{GA}-\mathrm{TiO}_{2}$ composites is a highly porous cylinder with a diameter of $1.5 \mathrm{~cm}$ and a height of $2 \mathrm{~cm}$ (Fig. 2a). The scanning electron microscopy (SEM) image of the $\mathrm{GA}^{-} \mathrm{TiO}_{2}$ composites clearly reveals that countless pieces of graphene sheets stack to form a loose interconnected structure with numerous micronsized voids (Fig. 2b), which well agrees with the GA structure (Fig. S2a $\dagger$ ). It is obvious that tiny $\mathrm{TiO}_{2}$ nanoparticles are uniformly and loosely attached to the graphene sheets, and no naked sheets or free $\mathrm{TiO}_{2}$ nanoparticles appear (Fig. 2c and d). The particle size of the $\mathrm{TiO}_{2}$ nanocrystals is about $5-10 \mathrm{~nm}$ and the edge of graphene can be clearly observed as indicated by the arrows in Fig. 2d. Furthermore, the well-defined crystalline lattice can be identified with the fringe spacing of 0.35 and $0.24 \mathrm{~nm}$ in high-resolution TEM image of the $\mathrm{GA}-\mathrm{TiO}_{2}$ composites (Fig. 2e), which well corresponds to the interplanar spacing of (101) and (001) facets of anatase $\mathrm{TiO}_{2}$, respectively. ${ }^{27}$ The polycrystalline nature of these individual $\mathrm{TiO}_{2}$ nanoparticles was also confirmed by the SAED measurements and several important features could be recognized (Fig. 2f). After the infusion of $\mathrm{S}$, the SEM image of $\mathrm{GA}-\mathrm{TiO}_{2} / \mathrm{S}$ composites (Fig. S3a $\dagger$ ) shows that the interconnected structure is still maintained. In the TEM image of the $\mathrm{GA}-\mathrm{TiO}_{2} / \mathrm{S}$ composites (Fig. 3a), no bulk S or S agglomerates are observed. The dark field TEM image and the elemental distributions of $\mathrm{C}, \mathrm{Ti}, \mathrm{O}$ and $\mathrm{S}$ of the $\mathrm{GA}-\mathrm{TiO}_{2} / \mathrm{S}$ composites (Fig. $3 \mathrm{~b}-\mathrm{f}$ ) further reveal the existence of uniform $\mathrm{TiO}_{2}$ nanoparticles and the infiltration of $\mathrm{S}$ into the $\mathrm{GA}-\mathrm{TiO}_{2}$ composites. It is clear that all the $\mathrm{GA}-\mathrm{TiO}_{2}-x$ composites have a similar loose interconnected structure with numerous micron-sized voids (Fig. S2c-f $\dagger$ ), indicating that the loading of $\mathrm{TiO}_{2}$ has no obvious influence on the 3D porous structure. In addition, the density of the nanoparticles on the surfaces of GA increases distinctly as the content of $\mathrm{TiO}_{2}$ rises.

The X-ray diffraction (XRD) pattern of the GA exhibits a weak and broad peak at around $25^{\circ}$ (Fig. 4), and the typical peak at $10^{\circ}$ corresponding to GO (Fig. S4 $\dagger$ ) disappears due to the reduction and self-assembly during the hydrothermal process. There are 7 noticeable diffraction peaks in XRD pattern of the GA- $\mathrm{TiO}_{2}$ composites, which are indexed to the (101), (004), (200), (105), (211), (204) and (215) facets of anatase- $\mathrm{TiO}_{2}$, respectively. Notably, the characteristic peak of GA located at $25^{\circ}$ is overlapped by the (101) peak of the $\mathrm{TiO}_{2}$. After the infusion of $S$, numerous $\mathrm{S}_{8}$ characteristic peaks are observable in the XRD patterns of the GA/S and $\mathrm{GA}-\mathrm{TiO}_{2} / \mathrm{S}$ composites, showing the successful incorporation of $\mathrm{S}$ into the original materials.

The $\mathrm{N}_{2}$ adsorption-desorption isotherms (Fig. S4a $\dagger$ ) of the GA and $\mathrm{GA}-\mathrm{TiO}_{2}$ composites both show type IV curves with distinct hysteresis loops close to $\mathrm{H} 3$ type, which is a typical characteristic of mesoporous structure. The specific surface area of the $\mathrm{GA}^{-} \mathrm{TiO}_{2}$ composites is calculated to be $360 \mathrm{~m}^{2} \mathrm{~g}^{-1}$, which is slightly less than that of the GA $\left(592 \mathrm{~m}^{2} \mathrm{~g}^{-1}\right)$. The decrease of the BET surface area can be explained by the introduction of the $\mathrm{TiO}_{2}$ particles. The pore size distribution of the GA and $\mathrm{GA}^{-} \mathrm{TiO}_{2}$ composites are both around $2.5 \mathrm{~nm}$ (Fig. S5b and $\mathrm{d} \dagger$ ). With the increase of $\mathrm{TiO}_{2}$ loading from 19 to $63 \mathrm{wt} \%$, the surface areas decrease from 486 to $297 \mathrm{~m}^{2} \mathrm{~g}^{-1}$.

The content of $\mathrm{TiO}_{2}$ in the $\mathrm{GA}^{-} \mathrm{TiO}_{2}$ composites are measured by thermogravimetric analysis (TG) (Fig. 5a). After the elimination of graphene in oxygen, the mass remains $42 \mathrm{wt} \%$, representing the $\mathrm{TiO}_{2}$ content in the $\mathrm{GA}-\mathrm{TiO}_{2}$ composites. Based on the TG result in nitrogen, the content of sulfur is as high as $70 \mathrm{wt} \%$ in both the $\mathrm{GA} / \mathrm{S}$ and $\mathrm{GA}-\mathrm{TiO}_{2} / \mathrm{S}$ composites. It is clear that this kind of 3D porous framework is able to hold a large amount of $\mathrm{S}$, which is beneficial for retaining the high areal capacity for the practical application. The $\mathrm{TiO}_{2}$ contents in other two $\mathrm{GA}-\mathrm{TiO}_{2}-x$ composites are determined to be 19 and $63 \mathrm{wt} \%$, respectively (Fig. S6a $\dagger$ ). To be fair, the contents of sulfur

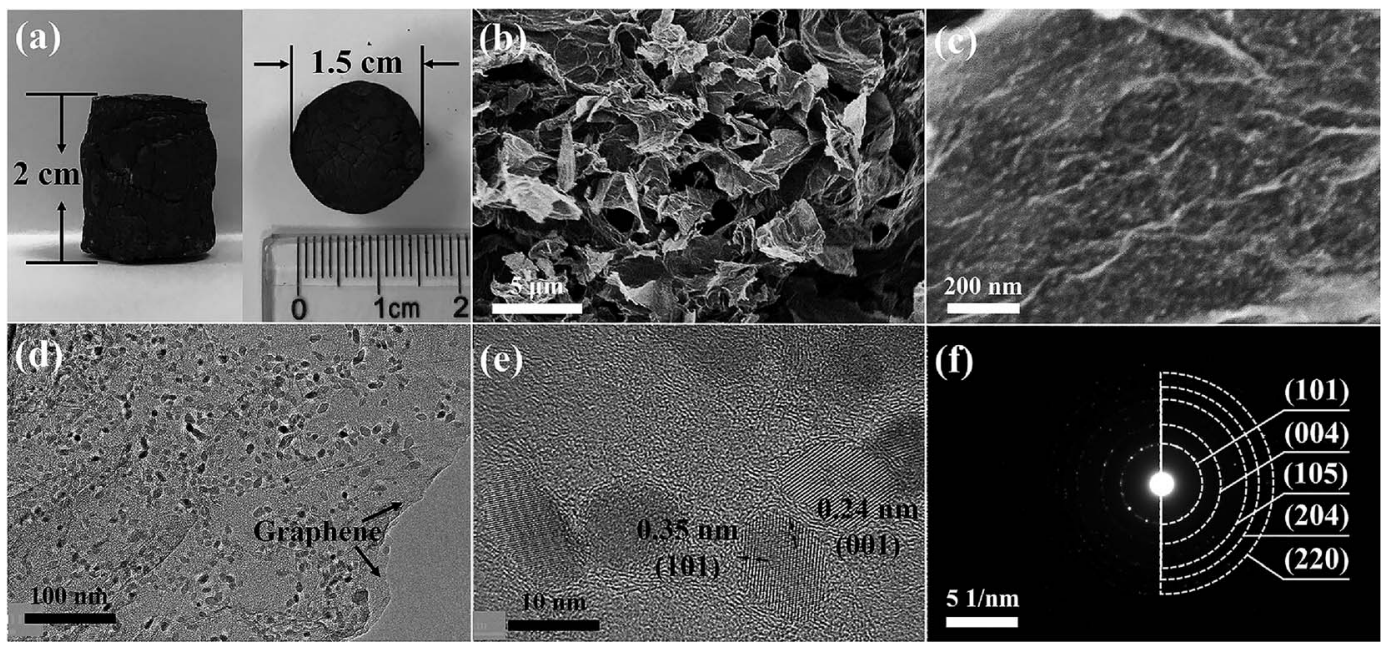

Fig. 2 (a) The macroscopic morphology of $\mathrm{GA}_{-} \mathrm{TiO}_{2}$. (b) Low-magnification SEM image and (c) high-magnification SEM image of GA-TiO 2. (d) Low-magnification TEM image and (e) high-resolution TEM image of $\mathrm{GA}-\mathrm{TiO}_{2}$. (f) The diffraction rings of $\mathrm{GA}_{-} \mathrm{TiO}_{2}$ analyzed through TEM. 


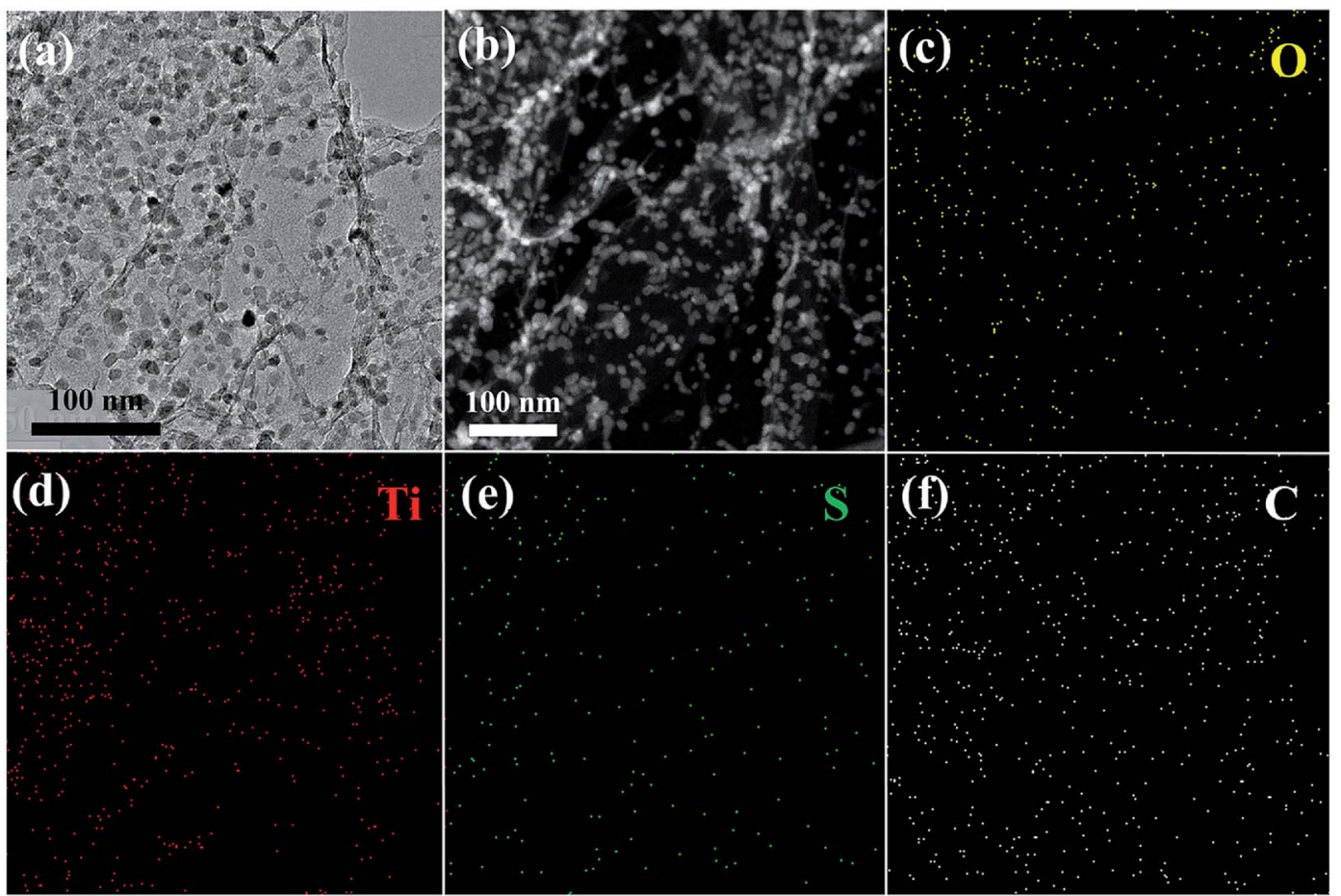

Fig. 3 (a) Low-magnification TEM image of $\mathrm{GA}-\mathrm{TiO}_{2} / \mathrm{S}$. (b) High-angle annular dark-field (HAADF) STEM image of $\mathrm{GA}-\mathrm{TiO} / \mathrm{S}$ with the corresponding elemental mapping of (c) $\mathrm{O}$, (d) $\mathrm{Ti},(\mathrm{e}) \mathrm{S}$, (f) $\mathrm{C}$.

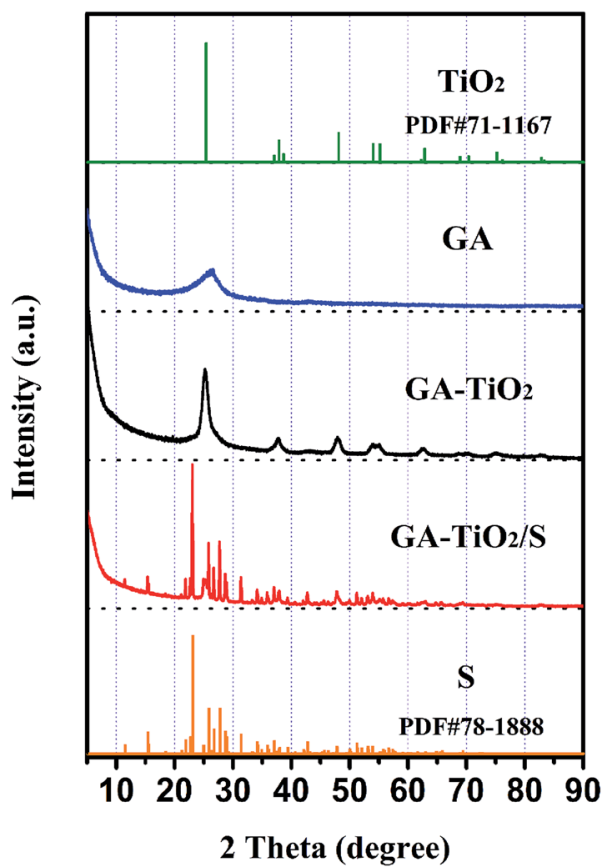

Fig. 4 XRD patterns of $\mathrm{TiO}_{2}, \mathrm{GA}, \mathrm{GA}-\mathrm{TiO}_{2}, \mathrm{GA}-\mathrm{TiO}_{2} / \mathrm{S}$ and $\mathrm{S}$.

in other $\mathrm{GA}^{-}-\mathrm{TiO}_{2}-x / \mathrm{S}$ are regulated to be about $70 \mathrm{wt} \%$ (Fig. S6b $\dagger$ ).

X-ray photoelectron microscopy (XPS) is used to investigate the possible interactions between $\mathrm{TiO}_{2}$ and $\mathrm{S}$. In the $\mathrm{S} 2 \mathrm{p}$ region of the $\mathrm{GA}-\mathrm{TiO}_{2} / \mathrm{S}$ composites (Fig. 5b), carbon sulfur (C-S) bonds at $163.8 \mathrm{eV}$ and $164.9 \mathrm{eV}$, and sulfur oxygen $(\mathrm{S}-\mathrm{O})$ bonds at $164.4 \mathrm{eV}$ and $165.4 \mathrm{eV}$ corroborate the strong chemical interaction between $\mathrm{GA}^{-} \mathrm{TiO}_{2}$ composites and the infused $\mathrm{S}^{28}$ The Ti $2 \mathrm{p}$ spectra of $\mathrm{GA}-\mathrm{TiO}_{2}$ and $\mathrm{GA}-\mathrm{TiO}_{2} / \mathrm{S}$ composites (Fig. $5 \mathrm{c}$ and d) both show typical $\mathrm{Ti}^{4+}$ characteristics with two peaks corresponding to $\mathrm{Ti} 2 \mathrm{p}_{1 / 2}(465.05 \mathrm{eV})$ and $\mathrm{Ti} 2 \mathrm{p}_{2 / 3}(459.2 \mathrm{eV})$ respectively. ${ }^{29}$ After $\mathrm{GA}^{-\mathrm{TiO}_{2}}$ composites being infused with $\mathrm{S}$, both the Ti $2 \mathrm{p}_{1 / 2}(464.9 \mathrm{eV})$ and $\mathrm{Ti} 2 \mathrm{p}_{2 / 3}(459 \mathrm{eV})$ characteristic peaks have a slight deviation to higher binding energy. The higher electronegativity of $\mathrm{S}$ results in the decrease of the electron density around $\mathrm{Ti}$ atom, and therefore, the binding energy of $\mathrm{Ti}$ increases. It is an evidence for the formation of SO-Ti bond. Especially, the exposed high energy (001) facets greatly facilitate the anchoring of $\mathrm{S}$ molecules on the surface of $\mathrm{TiO}_{2}$. The $\mathrm{O}$ 1s spectrum of the $\mathrm{GA}-\mathrm{TiO}_{2}$ composites (Fig. 5e) can be predominantly fitted into three distinct peaks. The peak at $530.4 \mathrm{eV}$ corresponds to oxygen bound to $\mathrm{Ti}^{4+}(\mathrm{Ti}-\mathrm{O})$ in $\mathrm{TiO}_{2}$ as well as the $\mathrm{C}=\mathrm{O}$ bond in $\mathrm{GA}^{30,31}$ The other two peaks at $531.2 \mathrm{eV}$ and $533.8 \mathrm{eV}$ can be referred to the hydrated oxygen $(\mathrm{OH}-\mathrm{C})$ and epoxide $(\mathrm{C}-\mathrm{O}-\mathrm{C})$, respectively. ${ }^{32}$ As for $\mathrm{GA}-\mathrm{TiO}_{2} / \mathrm{S}$ composites, the sulfur infusion has resulted in an extra characteristic peak at $532.1 \mathrm{eV}$, which can be assigned to oxygen bound to sulfur (O-S) (Fig. 5f).

To further demonstrate the interaction between the $\mathrm{TiO}_{2}$ nanoparticles and the polysulfides, an equivalent mass of the GA and $\mathrm{GA}-\mathrm{TiO}_{2}-42$ composites were added to $\mathrm{a}_{2} \mathrm{~S}_{6}$ solution $(0.01 \mathrm{M})$, separately. About an hour later, the solution containing the $\mathrm{GA}-\mathrm{TiO}_{2}$ becomes completely colorless, while the solution containing GA remained light yellow as shown in Fig. $5 \mathrm{~g}$. Subsequently, the GA/S and $\mathrm{GA}_{-}-\mathrm{TiO}_{2}-42 / \mathrm{S}$ composites are used 

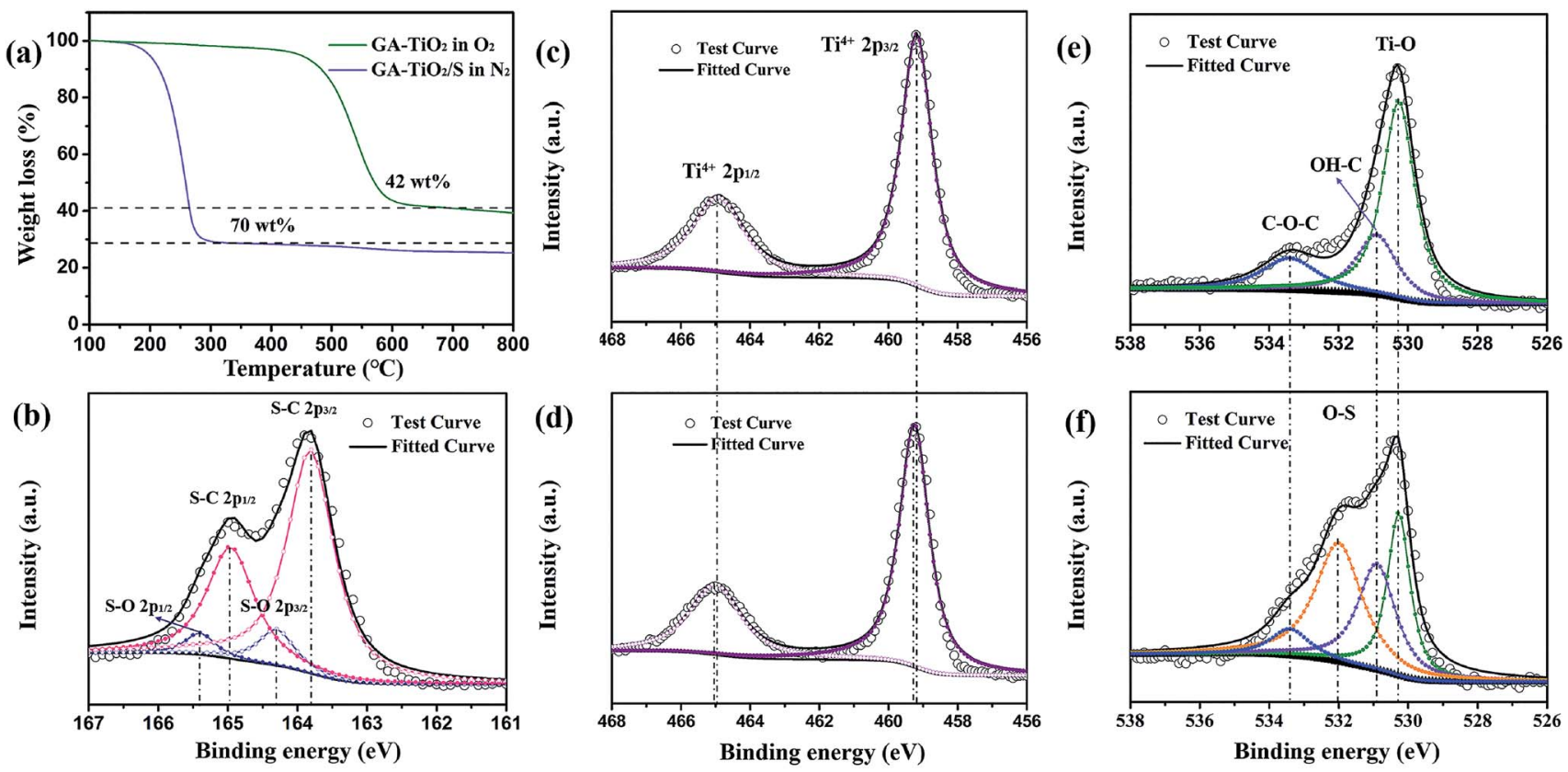

(g)

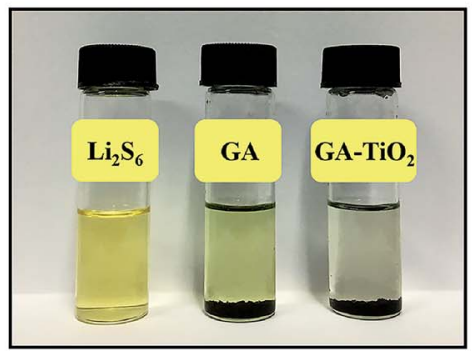

(h)

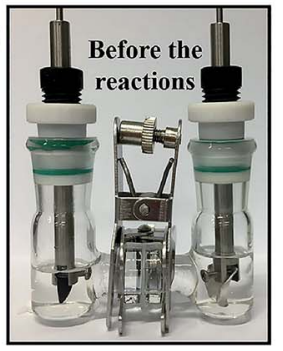

(i)

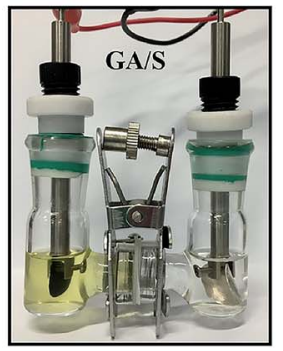

(j)

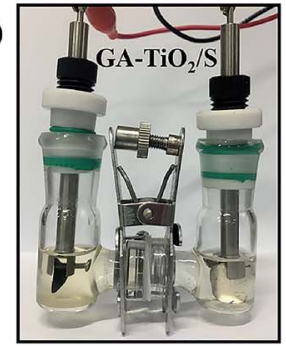

Fig. 5 (a) TG curves of $\mathrm{GA}-\mathrm{TiO}_{2}$ and $\mathrm{GA}-\mathrm{TiO}_{2} / \mathrm{S}$. (b) S $2 \mathrm{p}$ XPS curves of $\mathrm{GA}-\mathrm{TiO}_{2} / \mathrm{S}$. Ti $2 \mathrm{p}$ XPS spectra of (c) $\mathrm{GA}-\mathrm{TiO} \mathrm{O}_{2}$ and (d) GA-TiO $/ \mathrm{S}$. O $1 \mathrm{~s}$ XPS curves of (e) $\mathrm{GA}-\mathrm{TiO}_{2}$ and (f) $\mathrm{GA}-\mathrm{TiO}_{2} / \mathrm{S}$. (g) Optical photo of $\mathrm{Li}_{2} \mathrm{~S}_{6}$ solutions in DOM/DME (1: 1 by volume) with the immersion of GA and GA$\mathrm{TiO}_{2}$. Optical photos (h) before and after cycles using (i) $\mathrm{GA} / \mathrm{S}$ and (j) $\mathrm{GA}-\mathrm{TiO}_{2} / \mathrm{S}$ as cathode. The content of $\mathrm{TiO}_{2}$ in above samples is 42 wt\%.

as the cathodes and metallic lithium is used as the anode to form visible cells for further verifying the anchoring effect between the $\mathrm{TiO}_{2}$ particles and LiPSs. After the same number of 20 cycles at $0.1 \mathrm{C}$, the cell with $\mathrm{GA} / \mathrm{S}$ as the cathode displays yellow color (Fig. 5i), while the other with $\mathrm{GA}-\mathrm{TiO}_{2} / \mathrm{S}$ composites as cathode (based on the same mass of $\mathrm{S}$ in the cathode) gets only light yellow (Fig. 5j). Above results indicate that loaded $\mathrm{TiO}_{2}$ nanoparticles have strong chemical interaction with LiPSs during the charge and discharge processes.

The electrochemical properties of the $\mathrm{GA}^{-} \mathrm{TiO}_{2}-x / \mathrm{S}$ composites as a cathode material in Li-S batteries are investigated by assembling coin cells with metallic lithium as the anode. Typical cyclic voltammetry (CV) profiles of the GA/S and GA$\mathrm{TiO}_{2}-x / \mathrm{S}$ composites electrode all show two cathodic peaks and two anodic peaks (Fig. 6a, b and S6b $\dagger$ ). In the cathodic reduction process from 2 to 10 cycles, the two representative reductive peaks at approximately $2.3\left(v s . \mathrm{Li} / \mathrm{Li}^{+}\right.$, denoted as $\left.\mathrm{E} 1\right)$ and $2.07 \mathrm{~V}$ (denoted as E2) can be attributed to the reduction of sulfur to long-chain lithium polysulfides $\left(\mathrm{Li}_{2} \mathrm{~S}_{x}, 3 \leq x \leq 8\right)$ and the formation of short-chain $\mathrm{Li}_{2} \mathrm{~S}_{2} / \mathrm{Li}_{2} \mathrm{~S}$, respectively. Notably, after the participation of $\mathrm{TiO}_{2}$, the intensity of $\mathrm{E} 1$ is enhanced obviously and the potential moves to a higher voltage range narrower, suggesting the reaction kinetics $\left(\mathrm{S}_{8}+\mathrm{Li}^{+}+\mathrm{e}^{-} \rightarrow \mathrm{Li}_{2} \mathrm{~S}_{4}\right)$ at this potential is greatly enhanced. This result confirms that: $\mathrm{TiO}_{2}$ addition is beneficial for the transformation of soluble LiPSs to final insoluble $\mathrm{Li}_{2} \mathrm{~S}_{2} / \mathrm{Li}_{2} \mathrm{~S}$, which can substantially reduce the possibilities for the soluble LiPSs shuttling in the electrolyte. In the anodic scan, the anodic peaks at about $2.28 \mathrm{~V}$ (denoted as E3) and $2.36 \mathrm{~V}$ (denoted as E4) are identified as the oxidation of $\mathrm{Li}_{2} \mathrm{~S}_{2} / \mathrm{Li}_{2} \mathrm{~S}$ to intermediate polysulfides and the reverse conversion of polysulfides to sulfur, respectively. Compared with $\mathrm{GA} / \mathrm{S}, \mathrm{E} 4$ peaks of $\mathrm{GA}-\mathrm{TiO}_{2}-x / \mathrm{S}$ are more intense, which confirms that the existence of $\mathrm{TiO}_{2}$ can promote the reaction from soluble polysulfides to sulfur. This high reaction rate can greatly suppress the "shuttle effect". ${ }^{33}$ Besides, the peaks of the $\mathrm{GA}^{-} \mathrm{TiO}_{2}-x / \mathrm{S}$ are almost coincided with each other after four cycles, suggesting their excellent reversibility and capacity retention.

Corresponding to the peak current positions in the CV test, the charge-discharge profiles of the $\mathrm{GA}-\mathrm{TiO}_{2}-42 / \mathrm{S}$ consist of two discharge plateaus at 2.32 and $2.1 \mathrm{~V}$, and two charge plateaus between 2.26 and $2.35 \mathrm{~V}$ at $0.2 \mathrm{C}$ respectively. The GA/S electrode exhibits shorter plateaus flattering with a lower discharge capacity and a greater polarization under the same condition (Fig. S9 $\dagger$ ). When the $\mathrm{GA}^{-\mathrm{TiO}_{2}}-42 / \mathrm{S}$ electrode cycles at different rates of $0.1,0.2,0.3,0.5,1$ and $3 \mathrm{C}$, the cell is able to deliver 

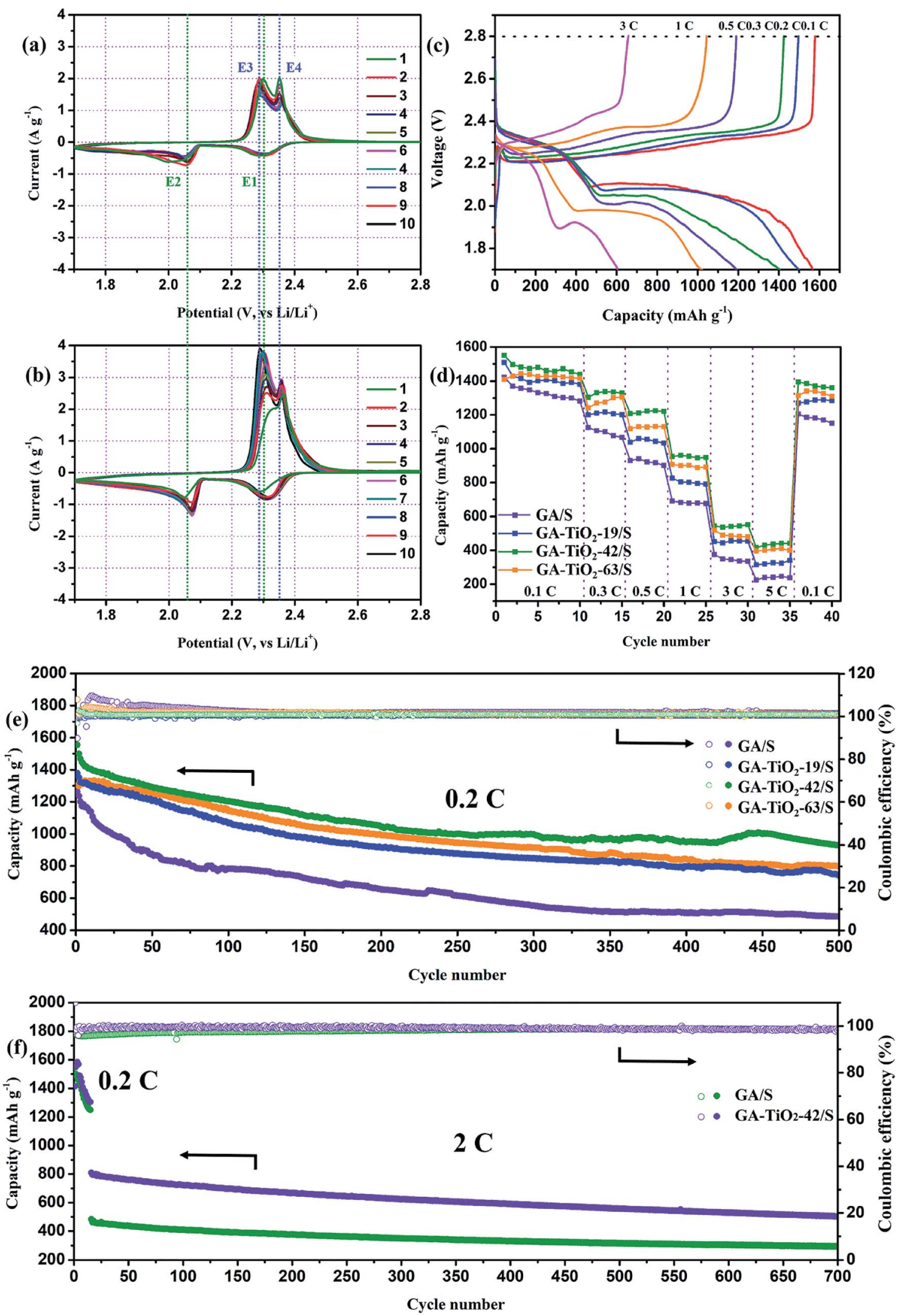

Fig. $6 \mathrm{CV}$ profiles of (a) $\mathrm{GA} / \mathrm{S}$ and (b) $\mathrm{GA}-\mathrm{TiO}_{2}-42 / \mathrm{S}$ cathodes at a scan rate of $0.05 \mathrm{mV} \mathrm{s}^{-1}$ in a potential window from 1.7 to $2.8 \mathrm{~V}$. (c) The second cycle galvanostatic charge-discharge profiles of $\mathrm{GA}-\mathrm{TiO}_{2}-42 / \mathrm{S}$ at 0.1, 0.2, 0.3, 0.5, 1 and 3C. (d) Rate performance of GA/S, GA-TiO $-19 / \mathrm{S}, \mathrm{GA}-$ $\mathrm{TiO}_{2}-42 / \mathrm{S}$ and $\mathrm{GA}-\mathrm{TiO}_{2}-63 / \mathrm{S}$ cathodes at different current densities. (e) Cycling performance and coulombic efficiency of GA/S, GA-TiO $2-19 / \mathrm{S}$, $\mathrm{GA}-\mathrm{TiO}_{2}-42 / \mathrm{S}$ and $\mathrm{GA}-\mathrm{TiO}_{2}-63 / \mathrm{S}$ cathodes at $0.2 \mathrm{C}$ for 500 cycles. (f) Cycling stability and Coulombic efficiency of the $\mathrm{GA}-\mathrm{TiO} \mathrm{O}_{2}-42 / \mathrm{S}$ and $\mathrm{GA} / \mathrm{S}$ cathode at $2 \mathrm{C}$ for 700 cycles. 
discharge capacities of 1567, 1497, 1404, 1190, 1022 and $604 \mathrm{~mA} \mathrm{~h} \mathrm{~g}^{-1}$ (Fig. 6c).

The rate capabilities of Li-S battery based on the GA/S or GA$\mathrm{TiO}_{2}-x / \mathrm{S}$ composites decrease gradually with the increase of current (Fig. 6d). However, the capacity of $\mathrm{GA}^{-} \mathrm{TiO}_{2}-42 / \mathrm{S}$ can maintain $396 \mathrm{~mA} \mathrm{~h} \mathrm{~g}^{-1}$ at $5 \mathrm{C}$, which is much higher than that of the GA/S (226 mA h g ${ }^{-1}$ ). Furthermore, after the current rate abruptly switched back to $0.1 \mathrm{C}$ after 35 cycles, the capacity of the $\mathrm{GA}_{-} \mathrm{TiO}_{2}-42 / \mathrm{S}$ composites can recover to $1395 \mathrm{~mA} \mathrm{~h} \mathrm{~g}{ }^{-1}$, indicating that $\mathrm{TiO}_{2}$ considerably enhances the electrochemical stability of Li-S batteries.

In the electrochemical impedance spectroscopy (EIS) measurements (Fig. S10 $\dagger$ ), the Nyquist plots of the GA/S and

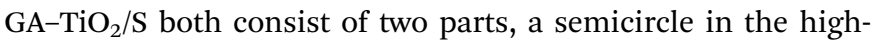
frequency region representing the interface charge transfer resistance at the electrode-electrolyte interface $\left(R_{\mathrm{ct}}\right)$ and a straight line in the low-frequency region associated with the mass transfer process. The $\mathrm{GA}-\mathrm{TiO}_{2} / \mathrm{S}$ cathode has the smaller $R_{\text {ct }}(53 \Omega)$ than that of the GA/S cathode (69 $\Omega$ ), indicative of better rate performance. After 100 cycles at $0.2 \mathrm{C}$, although the

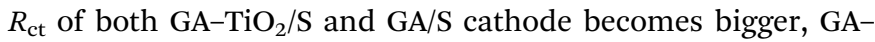
$\mathrm{TiO}_{2} / \mathrm{S}$ is still superior to GA/S cathode.

The cycling performances of the $\mathrm{GA} / \mathrm{S}$ and $\mathrm{GA}-\mathrm{TiO}_{2} / \mathrm{S}$ composites are presented in Fig. $6 \mathrm{e}$ and $\mathrm{f}$. It is clear that all the GA-TiO ${ }_{2} / \mathrm{S}$ composites show better cycling performances than that of the $\mathrm{GA} / \mathrm{S}$ at $0.2 \mathrm{C}$. Among the three $\mathrm{GA}^{-\mathrm{TiO}_{2}-x / \mathrm{S}}$ composites, the $\mathrm{GA}-\mathrm{TiO}_{2}-42 / \mathrm{S}$ displays the highest initial discharge capacity ( $1555 \mathrm{~mA} \mathrm{~h} \mathrm{~g}^{-1}$ ) and maintains the worthy reversible capacity ( $929 \mathrm{~mA} \mathrm{~h}^{-1}$ ) after 500 cycles with a nearly

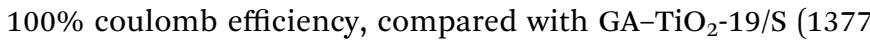
and $747 \mathrm{~mA} \mathrm{~h} \mathrm{~g}^{-1}$ ) and $\mathrm{GA}^{-\mathrm{TiO}_{2}}$-63/S (1302 and $800 \mathrm{~mA} \mathrm{~h} \mathrm{~g}^{-1}$ ) at $0.2 \mathrm{C}$. The capacity retentions over 500 cycles are calculated

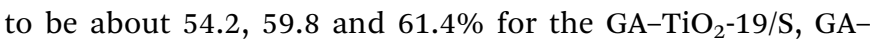
$\mathrm{TiO}_{2}-42 / \mathrm{S}$ and $\mathrm{GA}-\mathrm{TiO}_{2}-63 / \mathrm{S}$, respectively. It can be seen that the capacity retentions increase slightly as the content of $\mathrm{TiO}_{2}$ is raised. In addition, the discharge curve of $\mathrm{GA}^{-} \mathrm{TiO}_{2}-63 / \mathrm{S}$ has an activation process at the beginning, which can be ascribed to the low surface area and the poor conductivity. Because the infiltration of the electrolyte into the internal surfaces needs more time to make the hidden $\mathrm{S}$ become electrochemically active. This result confirms that: the $\mathrm{TiO}_{2}$ addition can greatly improve the cycling stability by restraining the shuttling of polysulfides, owing to the chemically adsorbing between the LiPSs and the $\mathrm{TiO}_{2}$ as well as the accelerated transformation from the soluble polysulfides to insoluble products. However, excessive additions are harmful to the reversible capacity due to the decline of electrical conductivity, which is in good accordance with the EIS results. When the current rate increases to a higher rate of $2 \mathrm{C}$ after an activated process (at $0.2 \mathrm{C}$ ), the $\mathrm{GA}^{-} \mathrm{TiO}_{2}-42 / \mathrm{S}$ electrode continues to maintain its superiority on the cycling performance with the initial discharge capacity of $810 \mathrm{~mA} \mathrm{~h} \mathrm{~g}^{-1}$, a low capacity loss $(0.054 \%$ per cycle) and a stable coulomb efficiency as high as $98.82 \%$ after 700 cycles.

The excellent electrochemical performance of the $\mathrm{GA}-\mathrm{TiO}_{2} / \mathrm{S}$ cathode in $\mathrm{Li}-\mathrm{S}$ batteries should ascribe to two factors. Firstly, the 3D hierarchical graphene-based framework not only

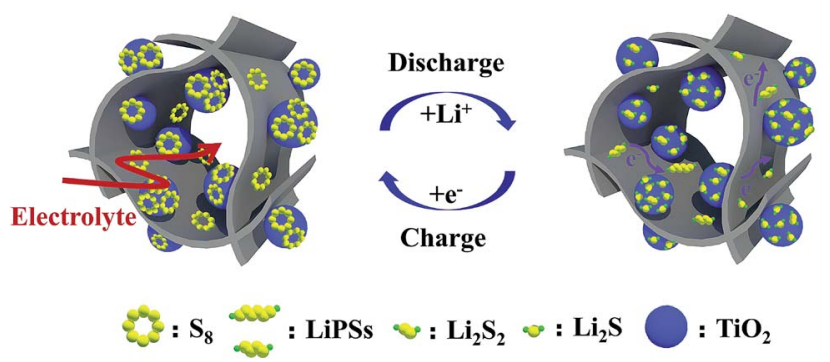

Fig. 7 The conversion of $\mathrm{S}$ during charge/discharge process on the graphene surface with $\mathrm{TiO}_{2}$ nanoparticles.

provides fast ion and electron transfer channels, but also affords enough space to accommodate the volume change of S. Secondly, as demonstrated in Fig. 7, uniform and ultradispersed anatase- $\mathrm{TiO}_{2}$ nanoparticles attached on the GA provide abundant polar surfaces to generate strong chemical anchoring effect on LiPSs, especially most of them expose high energy facets, which can effectively inhibit the "shuttle effect". Thirdly, the chemical interaction promotes the redox reaction kinetics during the charge and discharge processes, further greatly suppressing the shuttling of LiPSs.

Among current works, the electrochemical performance of the cathodes with graphene and/or $\mathrm{TiO}_{2}$ composites serving as the cathode materials of $\mathrm{Li}-\mathrm{S}$ batteries are compared in Table $\mathrm{S} 2 . \dagger$ The $\mathrm{GA}-\mathrm{TiO}_{2} / \mathrm{S}$ composites in this work stand out among all those Li-S energy-storage technologies because of the

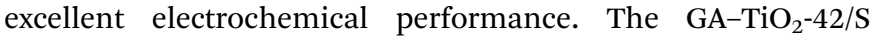
composites electrode with relatively high $\mathrm{S}$ content of $70 \mathrm{wt} \%$ exhibits an excellent initial specific capacity and cycle stability at $0.2 \mathrm{C}$. Even at a high current density of $2 \mathrm{C}$, it can be said that the $\mathrm{GA}-\mathrm{TiO}_{2}-42 / \mathrm{S}$ cathode presents the outstanding capacity among these studies and even beyond the performances of some materials at $1 \mathrm{C}$. Therefore, the $\mathrm{GA}-\mathrm{TiO}_{2}$ composites could achieve tremendous potential for the practical application of Li-S batteries.

\section{Conclusion}

In summary, large-scale $3 \mathrm{D} \mathrm{GA}^{-\mathrm{TiO}_{2}}$ composites can be synthesized by a facile hydrothermal treatment followed by high-temperature pyrolysis as a cathode material for $\mathrm{Li}-\mathrm{S}$ batteries. The $\mathrm{GA}-\mathrm{TiO}_{2}$ composites present an interconnected porous network structure with a controllable $\mathrm{TiO}_{2}$ loading and a high surface area of $297-486 \mathrm{~m}^{2} \mathrm{~g}^{-1}$. $\mathrm{TiO}_{2}$ is in the form of ultradispersed anatase nanoparticles (5-10 $\mathrm{nm}$ ) attached to the sheets of GA. When the $\mathrm{GA}-\mathrm{TiO}_{2}$ composites are used as a novel cathode material with a high sulfur loading of $70 \mathrm{wt} \%$, they restrain the "shuttle effect" and realize an excellent electrochemical performance in $\mathrm{Li}-\mathrm{S}$ batteries. Thus, the $\mathrm{GA}-\mathrm{TiO}_{2} / \mathrm{S}$ electrode exhibits a high specific capacity, a high-rate capability and a long cyclic stability with the coulombic efficiency reaching nearly $100 \%$ at various current densities, typically a high capacity of $810 \mathrm{~mA} \mathrm{~h} \mathrm{~g}^{-1}$ with an ultralow capacity fading of $0.054 \%$ per cycle over 700 cycles at $2 \mathrm{C}$. Above excellent results 
owing to the $\mathrm{GA}-\mathrm{TiO}_{2}$ composites combine the advantages of both the conductive 3D porous structure of 3D GA and the chemical interaction between $\mathrm{S} / \mathrm{LiPSs}$ and $\mathrm{TiO}_{2}$. This study provides the insights on the synergistic influence between nanostructure and chemical restrictions of $\mathrm{S}$ hosts for improving electrochemical performance of $\mathrm{Li}-\mathrm{S}$ batteries, and can be generalized for fabricating advanced cathode materials to accelerate the practical application of $\mathrm{Li}-\mathrm{S}$ batteries.

\section{Conflicts of interest}

There are no conflicts to declare.

\section{Acknowledgements}

This work was supported by the 973 program [2016YFA0204000], National Natural Science Foundation [No. 21473040 and No. 21603036], Science \& Technology Commission of Shanghai Municipality [No. 08DZ2270500] and Shanghai Rising-Star Program.

\section{Notes and references}

1 S. Urbonaite, T. Poux and P. Novák, Adv. Energy Mater., 2015, 5, 1500118.

2 W. Zhou, B. Guo, H. Gao and J. B. Goodenough, Adv. Energy Mater., 2016, 6, 1502059.

3 Y.-X. Yin, S. Xin, Y.-G. Guo and L.-J. Wan, Angew. Chem., Int. Ed., 2013, 52, 13186-13200.

4 A. Manthiram, Y. Fu and Y.-S. Su, Acc. Chem. Res., 2013, 46, 1125-1134.

5 A. Manthiram, Y. Fu, S.-H. Chung, C. Zu and Y.-S. Su, Chem. Rev., 2014, 114, 11751-11787.

6 R. Fang, S. Zhao, Z. Sun, D.-W. Wang, H.-M. Cheng and F. Li, Adv. Mater., 2017, 29, 1606823.

7 Z. W. Seh, Y. Sun, Q. Zhang and Y. Cui, Chem. Soc. Rev., 2016, 45, 5605-5634.

8 S. Li, B. Jin, X. Zhai, H. Li and Q. Jiang, ChemistrySelect, 2018, 3, 2245-2260.

9 H. Wang, Y. Yang, Y. Liang, J. T. Robinson, Y. Li, A. Jackson, Y. Cui and H. Dai, Nano Lett., 2011, 11, 2644-2647.

10 Y. Zhang, L. Wang, A. Zhang, Y. Song, X. Li, H. Feng, X. Wu and P. Du, Solid State Ionics, 2010, 181, 835-838.

11 J. Liang, Z.-H. Sun, F. Li and H.-M. Cheng, Energy Storage Materials, 2016, 2, 76-106.
12 Z. W. Seh, W. Li, J. J. Cha, G. Zheng, Y. Yang, M. T. McDowell, P.-C. Hsu and Y. Cui, Nat. Commun., 2013, 4, 1331.

13 B. Ding, L. Shen, G. Xu, P. Nie and X. Zhang, Electrochim. Acta, 2013, 107, 78-84.

14 Y. Tao, Y. Wei, Y. Liu, J. Wang, W. Qiao, L. Ling and D. Long, Energy Environ. Sci., 2016, 9, 3230-3239.

15 T. Ma, M. Liu, T. Huang and A. Yu, J. Power Sources, 2018, 398, 75-82.

16 Z. W. Seh, J. H. Yu, W. Li, P.-C. Hsu, H. Wang, Y. Sun, H. Yao, Q. Zhang and Y. Cui, Nat. Commun., 2014, 5, 5017.

17 Z. Cui, C. Zu, W. Zhou, A. Manthiram and J. B. Goodenough, Adv. Mater., 2016, 28, 6926-6931.

18 J. Zhou, R. Li, X. Fan, Y. Chen, R. Han, W. Li, J. Zheng, B. Wang and X. Li, Energy Environ. Sci., 2014, 7, 2715-2724.

19 S. Bai, X. Liu, K. Zhu, S. Wu and H. Zhou, Nat. Energy, 2016, 1, 16094.

20 M. Liu, F. Ye, W. Li, H. Li and Y. Zhang, Nano Res., 2016, 9, 94-116.

21 C. Li, Z. Xi, D. Guo, X. Chen and L. Yin, Small, 2018, 14, 1701986.

22 G.-N. Zhu, Y.-G. Wang and Y.-Y. Xia, Energy Environ. Sci., 2012, 5, 6652-6667.

23 H. B. Wu, J. S. Chen, H. H. Hng and X. W. Lou, Nanoscale, 2012, 4, 2526-2542.

24 S. K. Das, B. Jache, H. Lahon, C. L. Bender, J. Janek and P. Adelhelm, Chem. Commun., 2016, 52, 1428-1431.

25 S. Yang, X. Feng and K. Muellen, Adv. Mater., 2011, 23, 35753579.

26 B. Qiu, M. Xing and J. Zhang, J. Am. Chem. Soc., 2014, 136, 5852-5855.

27 H. B. Wu, J. S. Chen, X. W. Lou and H. H. Hng, Nanoscale, 2011, 3, 4082-4084.

28 L. Zhang, L. Ji, P.-A. Glans, Y. Zhang, J. Zhu and J. Guo, Phys. Chem. Chem. Phys., 2012, 14, 13670-13675.

29 K. Siuzdak, M. Szkoda, J. Karczewski, J. Ryl and A. LisowskaOleksiak, Electrochim. Acta, 2016, 222, 1281-1292.

30 H. Tang, S. Chang, K. Wu, G. Tang, Y. Fu, Q. Liu and X. Yang, RSC Adv., 2016, 6, 63117-63130.

31 Y. J. Oh, J. J. Yoo, Y. I. Kim, J. K. Yoon, H. N. Yoon, J.-H. Kim and S. B. Park, Electrochim. Acta, 2014, 116, 118-128.

32 B. Lim, M. Jiang, P. H. C. Camargo, E. C. Cho, J. Tao, X. Lu, Y. Zhu and Y. Xia, Science, 2009, 324, 1302-1305.

33 Z. Sun, J. Zhang, L. Yin, G. Hu, R. Fang, H.-M. Cheng and F. Li, Nat. Commun., 2017, 8, 14627. 